Please send trade news information and illustrations to Arveen Bajaj at the BDJ, 64 Wimpole Street, London W1G 8YS. Trade news is supplied as a service to the reader and does not imply endorsement by the BDJ. Normal and prudent research should be exercised before purchase of use of any product mentioned.

\section{TRADE NEWS \\ WHAT'S NEW}

\section{New pack available}

Colgate has opened registration for its 2004 Colgate Oral Health Month Practice Pack.

In partnership with the BDA, Colgate Oral Health Month is in its third year and takes place this September.

The new pack was developed based on the views of previous participants and will contain educational booklets, patient toothpaste and mouth rinse samples, posters, a patient competition and other fun patient items.

The pack will be delivered by the end of August and one pack per practice is permitted, subject to availability.

Practices who would like to register should look out for the registration cards over the coming month or alternatively call the Customer Care Team on 01483401901.

All registrations must be received by the 31st August 2004.

Reader response number 50

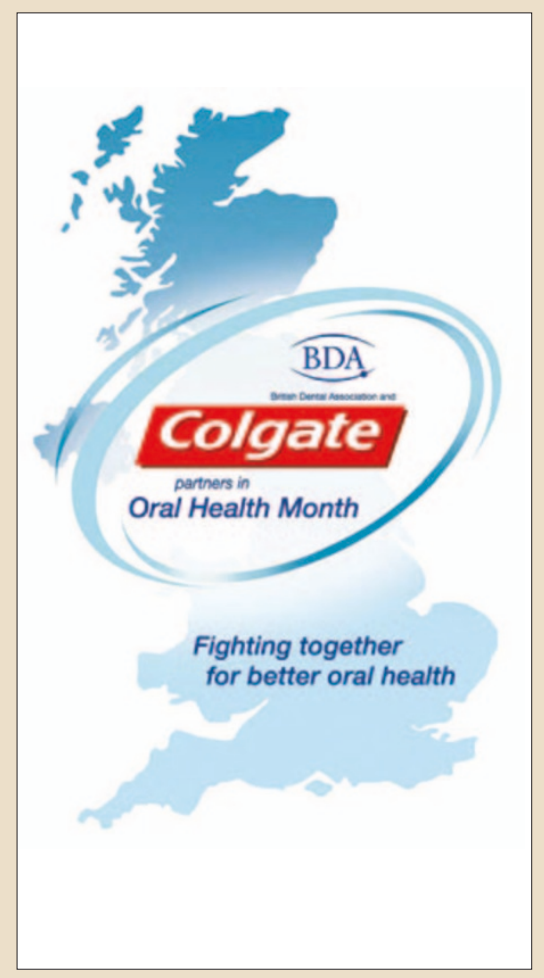

\title{
Range expanded
}

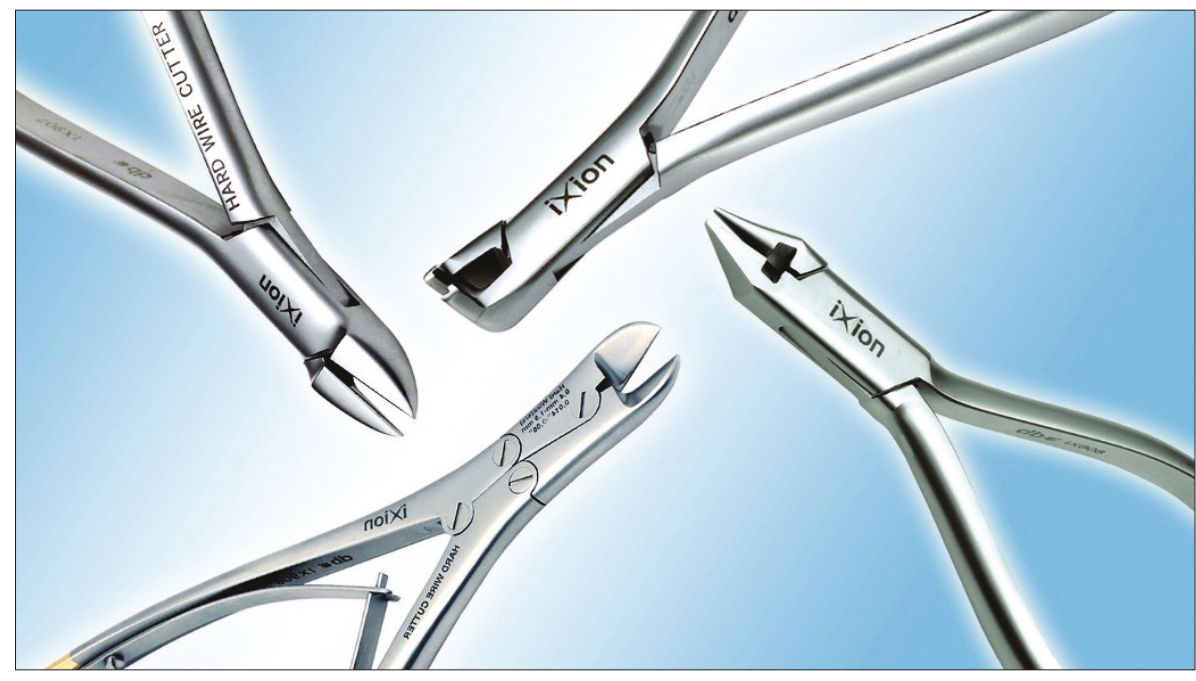

DB Orthodontics Limited have extended their range of Ixion Orthodontic Instruments with the addition of five new instruments. All the square edges on the handles and head of the pliers have been replaced with smooth rounded contours for comfort.

They are all constructed from German stainless steel with a satin finish, which reduces glare from surgery lighting and offers durability providing proper care guidelines are followed, according to the company.

All the cutting edges are made from tungsten carbide, which contributes to strength and sharpness.

Reader response number 51

\section{New generation chair}

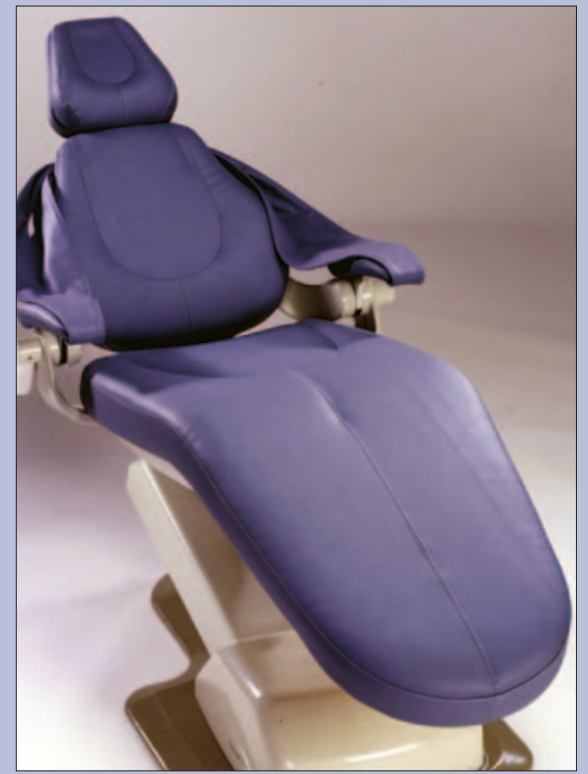

DentalEZ have introduced the $\mathrm{J} / \mathrm{V}$ Generation Chair.

The Generation has a new modern design and an exclusive independent seat tilt feature allowing precise positioning of the patient, according to its makers.

Arm slings and a thin narrow back allow the dentist better access to the oral cavity and the anatomically correct hip pivot point increases patient comfort during long procedures.

Eight programmable positions plus manual controls for base, backrest and seat tilt reduces the time needed for adjustment.

The $\mathrm{J} / \mathrm{V}$ Generation Chair is supplied in Ultraleather Plush upholstery. Reader response number 52 

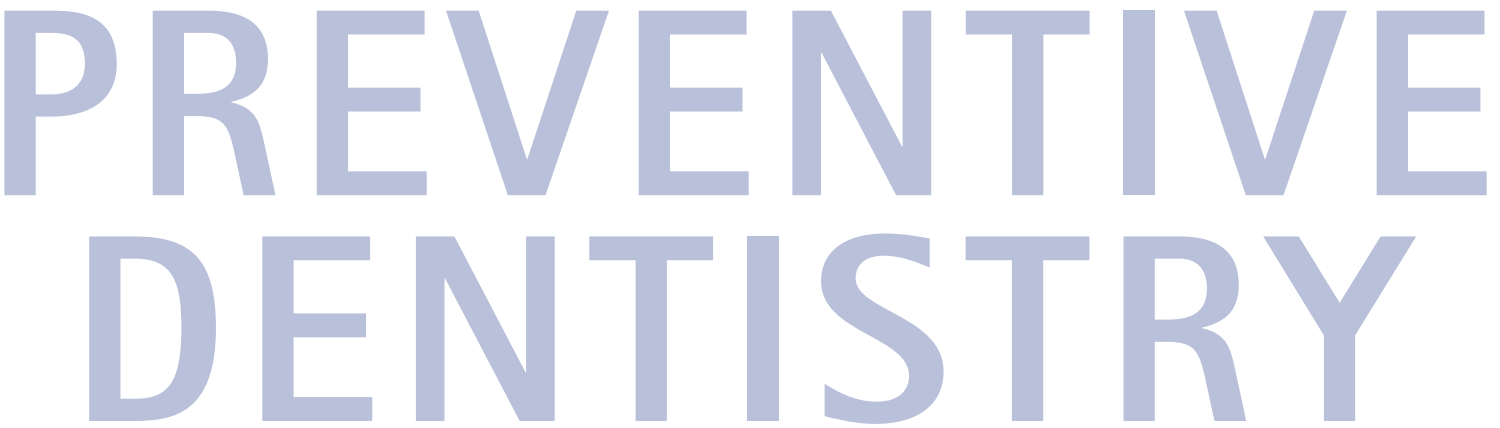

\section{Communication tool}

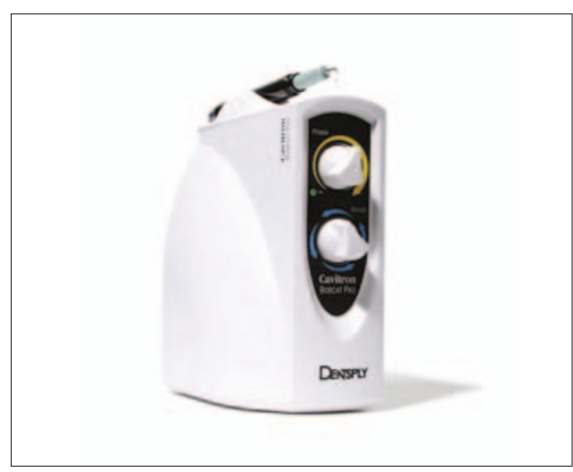

Dentsply has announced the arrival of the Cavitron Bobcat Pro, which will replace the previous model. It works with existing $25 \mathrm{kHz}$ Cavitron inserts, and its ultrasonic scaling removes plaque, calculus and staining, according to the company.

Its design means that it also reduces the potential for flipping over and the need to correct the position during a procedure. It will also stand horizontally or vertically. Dentsply is currently offering a $£ 50.00$ trade in against the new unit for your old scaling unit until 30th September 2004.

Reader response number 53

\section{Healing properties}

Gengigel from Oraldent can aid the healing process, according to the manufacturers. Its principal ingredient is hyaluronan which applies its healing properties to maintaining the integrity of gingival and periodontal tissue after surgical trauma, combating inflammation and accelerating the process of tissue repair.

Gengigel is available in mouth rinse and gel formats to be used in the surgery or at home for patient convenience.

\section{Reader response number $\mathbf{5 5}$}
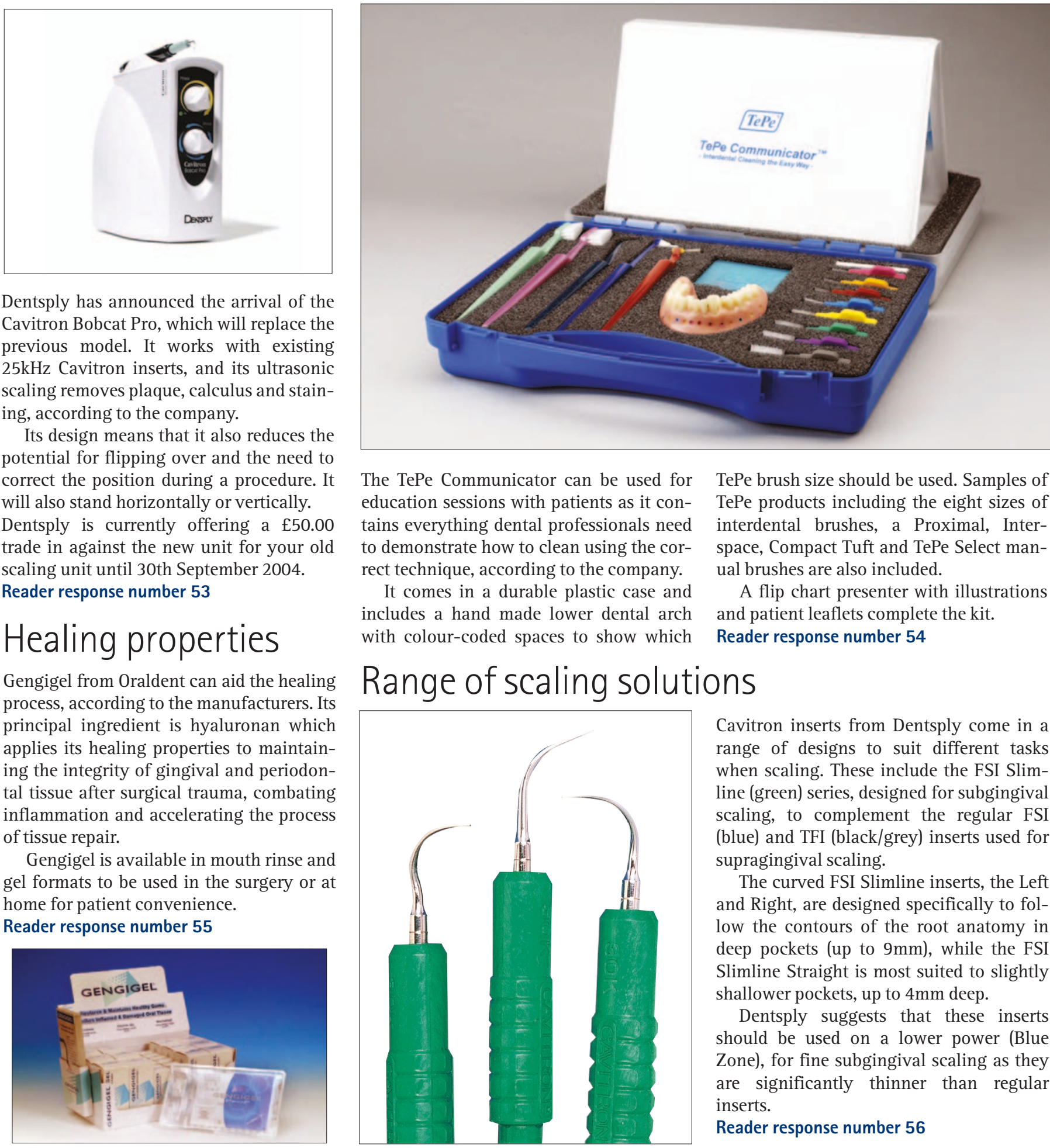

The TePe Communicator can be used for education sessions with patients as it contains everything dental professionals need to demonstrate how to clean using the correct technique, according to the company.

It comes in a durable plastic case and includes a hand made lower dental arch with colour-coded spaces to show which

\section{Range of scaling solutions}

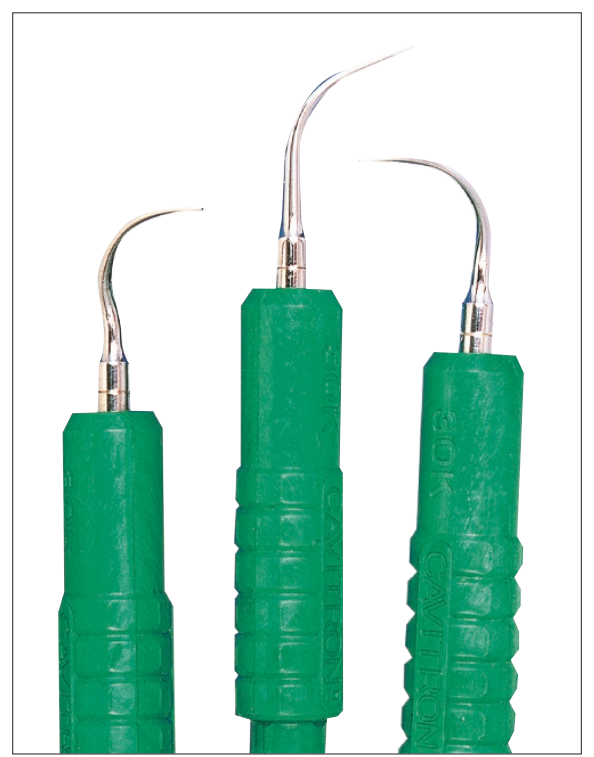
inserts.
TePe brush size should be used. Samples of TePe products including the eight sizes of interdental brushes, a Proximal, Interspace, Compact Tuft and TePe Select manual brushes are also included.

A flip chart presenter with illustrations and patient leaflets complete the kit.

Reader response number 54

Cavitron inserts from Dentsply come in a range of designs to suit different tasks when scaling. These include the FSI Slimline (green) series, designed for subgingival scaling, to complement the regular FSI (blue) and TFI (black/grey) inserts used for supragingival scaling.

The curved FSI Slimline inserts, the Left and Right, are designed specifically to follow the contours of the root anatomy in deep pockets (up to $9 \mathrm{~mm}$ ), while the FSI Slimline Straight is most suited to slightly shallower pockets, up to $4 \mathrm{~mm}$ deep.

Dentsply suggests that these inserts should be used on a lower power (Blue Zone), for fine subgingival scaling as they are significantly thinner than regular

Reader response number 56 


\section{Low viscosity sealant}

Delton DDS Pit and Fissure Sealant from Dentsply has low viscosity and smooth flowing, non-sticky properties which can ensure absolute penetration of the fissure and intricate interdental spaces, the company claims.

In addition, with the increasing importance placed on cross-infection control, the Delton DDS (lightcured) unit dose can minimise the risks of patient-to-patient contamination. Delton is an integral part of

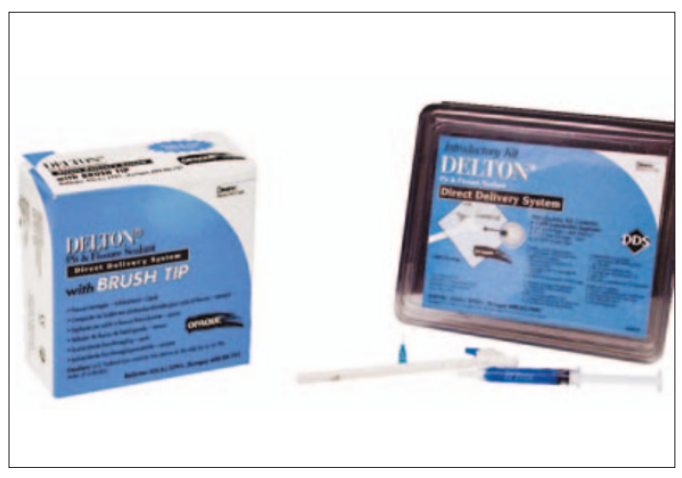
the Dentsply prophy range, which includes Nupro Prophylaxis Paste (in jars and unit cups for cross infection control) and the Cavitron SPS-Jet, which can be used for effective fissure cleaning.

Reader response number 57

\section{Product to combat flossing fatigue}

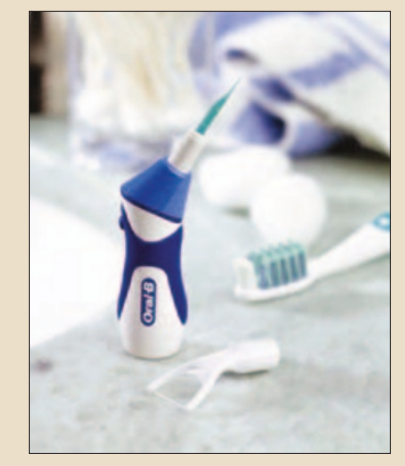

Oral-B's latest pioneering product is designed to combat 'flossing inertia' amongst patients. It is a power pick and flosser called Hummingbird which gently vibrates to make flossing a more comfortable experience.

Hummingbird is extremely compact ensuring that it manoeuvres easily around the oral cavity and can access interproximal spaces even in posterior regions, areas 'finger flossers' find cumbersome according to Oral-B.

Reader response number 58

\section{Summer sizzler}

Dentists can save over 17\% when purchasing a 'Summer Surgery Pack' from Kemdent. The surgery pack contains Diamond, Kemdent's special GPC (glass polyposphonate cement) restorative in a choice of 7 Vita matched shades, Kemdent Prophylaxis Paste, Ruwa Matrix Strips and Detex Articulating paper plus a free sample pack of Mouthwash Tablets. The 'Summer Surgery Pack' costs £45.00. Customers buying two or more packs receive a further $10 \%$ discount. When ordering please quote SSMP.

Reader response number 59

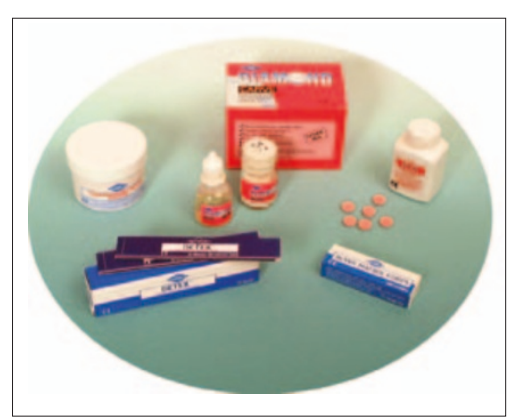

\section{High fluoride formulation}

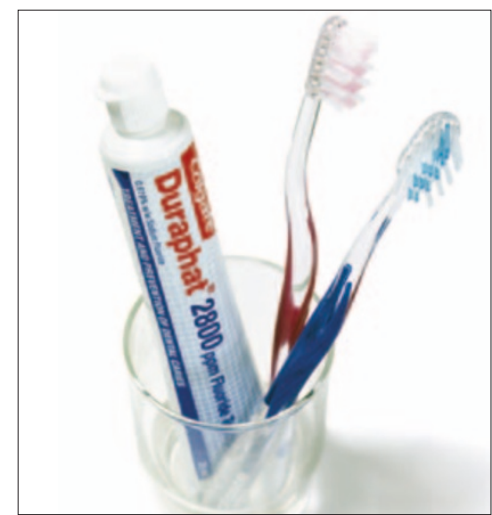

Colgate Duraphat 2800 Fluoride Toothpaste is the only toothpaste available in the UK to contain twice as much fluoride as regular toothpaste. This high fluoride formulation means that it is available as a Prescription Only Medicine (POM).

It is specially formulated for adults and children over 16 years of age with early caries lesions and those who require extra protection such as adults with gingival recession, heavy restorations, orthodontic appliance wearers and elderly patients, including those with reduced salivary flow.

Reader response number 60 